\title{
Economies of vertical integration in the Swiss electricity sector ${ }^{1}$
}

\author{
Aurelio Fetz, Massimo Filippini \\ Department of Management, Technology and Economics, ETH Zurich \\ Zurichbergstr. 18, CH-8032 Zurich, Switzerland \\ Tel. +41-44-63206 50, Fax. +41-44-632 1050 \\ and \\ Department of Economics, University of Lugano \\ afetz@ethz.ch,.mfilippini@ethz.ch
}

\begin{abstract}
Over the last two decades, several European nations have introduced reforms to their electricity sector. Generally, these reforms require a legal and functional unbundling of vertically integrated companies. These unbundling processes may reduce the possibilities that exist to fruitfully exploit the advantages of vertical integration.

The goal of this paper is to empirically analyze the presence of economies of scale and vertical integration in the Swiss electricity sector. Economies of vertical integration between electricity production and distribution result from reduced transaction costs, better coordination of highly specific and interdependent investments and less financial risk. Different econometric specifications for panel data, including a random effects and a random-coefficients model, have been used to estimate a quadratic multi-stage cost function for a sample of electricity companies. The empirical results reflect the presence of considerable economies of vertical integration and economies of scale for most of the companies considered in the analysis. Moreover, the results suggest a variation in economies of vertical integration across companies due to unobserved heterogeneity.

JEL Classification: C33, D24, L11, L25, L94, L95
\end{abstract}

\footnotetext{
${ }^{1}$ We gratefully acknowledge the insightful comments and help from Mehdi Farsi. All remaining errors and omissions are ours. The views expressed in this paper do not necessarily reflect the position of any sponsoring agency.
} 


\section{Introduction}

Several European countries have embraced new and modern reforms to their electricity sector over the past two decades. The general principles adopted in these reforms included the introduction of competition in electricity generation and the introduction of new regulatory instruments such as the price cap method in the transmission and distribution of electricity, still considered natural monopolies.

These reforms have introduced some changes to the managerial organization of electric utilities, traditionally maintained as vertically integrated utilities with generation, transmission and distribution under a common corporate roof. For instance, the directive 2003/54/EC of the European Parliament and of the EU Council of 26 June 2003 requires a legal and functional unbundling of the utilities. ${ }^{2}$ Generally, the vertically integrated companies are required to separate the production, transmission and distribution functions.

The thesis behind this policy is that unbundling the services into separate functions allows greater efficiency through stronger and more transparent competition in the generation and sale activities of this sector. Not only does unbundling reduce the possibilities of crosssubsidizing generation activities with transmission activities, it also curtails the possibility of limiting the access to the network for competing generators.

However, one has to consider that unbundling processes reduce the possibilities that exist to exploit the advantages of vertical integration. In fact, a vertically integrated structure can be cost effective if there is a substantial need for coordination across stages and if high transaction costs are associated with using intermediary markets. This means that policymakers should be concerned about the efficient balance between integration and unbundling. ${ }^{3}$ According to the EU policy directive, EU member states can exempt utilities with fewer than 100,000 customers from any functional unbundling requirement of the distribution network. In this case, the EU seems to

\footnotetext{
2 The EU distinguishes five main types of such unbundling: 1. Accounting unbundling; 2. Functional unbundling (separate accounts and management for transmission and generation activities); 3. Legal unbundling (transmission and generation are separate legal entities); 4. Ownership unbundling (generation and transmission have to be owned by independent entities).

${ }^{3}$ The welfare implications of this policy results from the magnitude of the price savings associated with the introduction of competition and the cost increases caused by a reduction of the exploitation of vertical economies. Unfortunately, no study at the European level has systematically analyzed these welfare implications.
} 
consider that for relatively small electric utilities the economies of vertical integration are considerable.

Economies of vertical integration between electricity production and distribution result from reduced transaction costs; better coordination of highly specific and interdependent investments in generation, transmission and distribution; less financial risk due to higher certainty in the sale activities; and avoiding the hold-up problem from technological interdependencies in different production stages. ${ }^{4}$ A reduction in transaction costs implies a drop in the coordination costs for daily activities in the coordination costs of planning a reliable, and least-cost production and transmission system, and a cut in the negotiation costs. ${ }^{5}$

Despite its policy importance, only a few studies have estimated directly the economies of vertical integration in the electricity sector. Kaserman and Mayo (1991), Kwoka (2002), and Isaacs (2006) estimated a quadratic multi-stage cost function for a cross section of US electricity companies. Jara-Diaz, Martinez-Budria et al. (2004) estimated a quadratic multi-stage cost function for a sample of Spanish electricity companies using panel data, whereas Fraquelli, Piacenza et al. (2005) estimated a composite multi-stage cost function with a log-quadratic input price structure and a quadratic output structure using panel data for a sample of Italian utilities. Recently, Greer (2008) estimated a multi-stage, multi-output cost function for a cross section of US rural electric cooperatives. In general, all studies found that economies of vertical integration exist. Moreover, these studies indicate that larger utilities exploit a higher degree of economies of vertical integration. ${ }^{6}$

The purpose of this paper is to make a contribution to the empirical literature on the economies of vertical integration using panel data for a sample of Swiss electricity distribution utilities. This analysis has important policy implications in view of the ongoing electricity market reforms in Switzerland as well in several European countries, especially for discussion on the ex-

4 The organization of the electricity industry in several production stages (generation, transmission and distribution) implies that generators need transmission and distribution to get electricity to consumers and that transmission and distribution assets need generators. In this situation, the generator, transmission and distribution assets, created and independently owned, cannot be dedicated to other uses. Therefore, either side can 'hold up' the other.

${ }^{5}$ For a detailed discussion on the sources of the economies of vertical integration in the electricity industry see Michaels (2004).

${ }^{6}$ Other methodologies to analyze if vertical effects exist are by separability test of cost functions (see Lee (1995) and Hayashi, Goo et al. - 1997) and by the estimation of cost complementarities (see Gilsdorf (1994), and Ida and Kuwahara - 2004). However, these approached do not allow quantifying the effects. 
emption limit for the functional unbundling requirement of three activities--generation, transmission and distribution. ${ }^{7}$

From a methodological point of view, one of the major difficulties in estimating economies of vertical integration is that different networks, environmental and technical characteristics can typify vertically integrated and vertically disintegrated electricity companies. From the empirical analysis point of view, many of these characteristics are not observed or are difficult to measure--and therefore, not included in the cost model specification. Such an omitted-variables problem could bias the estimation results. Moreover, the strong heterogeneity among utilities suggests that a cost function with constant coefficients might be inadequate for a reliable analysis of economies of vertical integration.

In this study, to account at least partially for such heterogeneity and to perhaps assess the potential biases, we use some econometric specifications for panel data. To our knowledge, only the study by Jara-Diaz, Martinez-Budria et al. (2004) has used the advantages of panel data models to account for heterogeneity among companies. However, the approach used by these authors, a fixed effects model, is able to only partially consider the effect of the unobserved heterogeneity on the coefficients of the econometric model.

In this paper we estimate a multi-stage cost function using two panel data econometric models, a Generalized Least Squares (GLS) model with random intercept and a random coefficients (RC) model. The data set comprises 74 Swiss electricity companies observed during the period between 1997 and 2005. The sample includes both specialized and integrated companies.

This paper is organized as follows. Section 2 presents the model specification and the estimation methods; Section 3 describes the data; Section 4 presents the regression results; the definition of economies of vertical integration and economies of scale and their estimates are discussed in Section 5; the paper ends with a summary of main results and policy conclusions.

\footnotetext{
${ }^{7}$ Although Switzerland does not belong to the European Union, the Swiss electricity market reform has introduced some unbundling requirements. For instance, the large interregional high-voltage transmission network has been functionally unbundled. Moreover, the small and middle-sized electricity companies have introduced an accounting and informational unbundling. To note, that the Swiss reform does not foresee a formal exemption limit for the functional unbundling of the different activities. However, because the majority of the Swiss companies have less than 100 ’000 customers, implies indirectly an acceptance of the European limit.
} 


\section{Model specification}

Empirical studies on the cost structure of vertically integrated electricity utilities and of specialized utilities assume total cost as a function of output, price of inputs and some output characteristic variables such as area size, customer density and load factor. Generally, these output characteristic variables are introduced in the model to capture heterogeneity in the output and in the different service areas. Most of these studies also include a time trend to control for potential changes in the technology.

For the empirical analysis of this paper we considered a sample of small and middle-sized electricity companies. While some of them are vertically integrated companies, others are active only in the distribution of electricity. Vertically integrated companies are characterized by the presence of hydropower plants, a small high voltage transmission network, and a regional distribution network.

The model specification used in this study is based on a cost function with two outputs (electricity generation and distribution), two inputs, three output characteristic variables, and a linear time trend. As in Sing (1987), Kwoka (2002), Filippini, Hrovatin et al. (2004) and Fraquelli, Piacenza et al. (2005) customer density is introduced as a service area characteristic. Furthermore, the load factor of the network and the capacity utilization factor at the generation level are also included in the model to control differences in the load profiles across the companies. $^{8}$

Following Kwoka (2002), the share of the sales to end consumers has also been introduced in the cost model. In fact, distribution to end consumers needs more transformation and more infrastructures compared with distribution to resellers, and is therefore assumed to be related to higher losses and higher costs. We are aware that these output characteristics variables consider just one part of the heterogeneity of the electric companies included in this study. However, as we will see later, part of the unobserved characteristics variables will indirectly be taken into account using panel data econometric models.

\footnotetext{
${ }^{8}$ See also studies by Gilsdorf (1995), Filippini (1996) and (1998), Yatchew (2000) and Filippini, Hrovatin et al. (2004) which included the load factor of the network and studies by Maloney (2001), Kwoka (2002), Ida and Kuwahara (2004) and Jara-Diaz, Martinez-Budria et al. (2004) where the generation capacity utilization factor was included.
} 
If it is assumed that the firm minimizes cost and that the technology is convex, a total cost function can be written as:

$C=C(Q 1, Q 2, P C, P L, C D, E C, L F, C U, T)$

where $C$ represents total costs; $Q 1$ and $Q 2$ are respectively the electricity generated and electricity distributed during the year; $P L$ and $P C$ are respectively the input factor prices for labour and capital services ${ }^{9}$; $C D$ is the customer density; $E C$ is the share of the distributed electricity to end consumers; $L F$ is the load factor of the network; and $C U$ measures the generation capacity utilization. Finally, $T$ is a linear time trend controlling for technical change.

For the estimation of the total cost (1), it is necessary to choose a functional form. With a growing number of functional forms available, the model builder's task is getting complicated. A comparison of the different functional forms requires some a priori selection criteria which should refer to mathematical, econometric and economic properties. For the estimation of multistage cost functions in the electricity sector, most of the studies have used a quadratic functional form. Recently, Fraquelli et al. (2004) used a general specification of the composite cost function model proposed by Pulley and Braunstein (1992). This is a non-linear functional form that nests the standard translog cost function, the generalized translog cost function, and the separable quadratic cost function.

This means that from a mathematical point of view this functional form is more flexible. That is, it imposes lesser restrictions than the other classical functional forms. However, from the econometric point of view, this functional form can present some drawbacks. For instance, in the presence of panel data, the quadratic functional form can be easily estimated using several econometric specifications for panel data, whereas the estimation of the non-linear model of Pul-

\footnotetext{
${ }^{9}$ In a study by Jara-Diaz et. al. (2004) 4 input prices have been included in the cost model: capital, labor, fuel price, and a price for an intermediate input. In this model we decided to exclude the latter two input prices for the following reasons. The electricity companies included in our sample produce electricity using hydropower plants. For the use of water ("fuel”) these companies have to pay a fixed fee per kw to the local government. This water fee is the same for all companies (80 Swiss francs per $\mathrm{kW}$ ). This implies that this variable cannot be included in the model. Further, it is not clear how to specify the price for the intermediary input because, as pointed out by Jara-Diaz et. al. (2004), the reference inputs behind this measure is highly heterogeneous. For this reasons we preferred to use a simpler specification.
} 
ley and Braunstein (1992) is not straightforward. ${ }^{10}$ As we will discuss later, some econometric specifications for panel data have the advantage of reducing potential bias in empirical results due to unobserved heterogeneity.

Given the potential importance of unobserved heterogeneity in the model and given the possibility to take it into account, we focus here on the quadratic functional form which was introduced by Baumol, Panzar et al. (1982) and applied among others by Mayo (1984). This form is readily adaptable to panel data econometric models and has been considered as one of the most relevant options for estimating scope economies (Tovar, Jara-Diaz et al. - 2007). ${ }^{11}$ In addition, unlike logarithmic forms, the functional form accommodates zero values for outputs, thus allowing an inclusion of specialized companies and a straightforward identification of economies of vertical integration.

Although logarithmic functions could be used with an arbitrary small value transformation for zero values, it has been shown that this approach could result in large errors in the estimation of scope economies (Pulley and Humphrey - 1993). As in our case, many output values for electricity generation and distribution are zero. Such estimation errors may result in misleading conclusions about the economies of vertical integration. One disadvantage of the quadratic form is that the linear homogeneity of the cost function in input prices cannot be imposed by parametric restrictions without sacrificing the flexibility of the functional form (Caves, Christensen et al. 1980). However, the linear homogeneity in input prices can be imposed by normalization of prices namely, by dividing the costs and all factor prices by one common factor price ${ }^{12}$

\footnotetext{
${ }^{10}$ For example, Fraquelli, Piacenza et al. (2004) analyze the economies of vertical integration for a sample of Italian companies using panel data and applying several non-linear functional forms. However, from the econometric point of view, panel data econometric models have not been used. In this case, the authors have given a legitimate importance to the flexibility dimension of the functional form.

${ }^{11}$ See Farsi, Fetz et al. (2008) for the use of the quadratic functional form with several panel data models.

12 See Farsi, Fetz et al. - (2007), and Jara-Diaz, Martinez-Budria et al. - 2003.
} 
The quadratic form is a flexible functional form with a second-order Taylor approximation of any arbitrary function around a local approximation point. In this paper the sample mean has been used as the approximation point following the commonly used approach in the literature (e.g. Jara-Diaz, Martinez-Budria et al. - 2003). ${ }^{13}$ The adopted normalized quadratic cost function specification can be written as follows:

$$
\begin{aligned}
& C_{i t}=\alpha_{0}+\alpha_{Q 1} Q 1_{i t}+\alpha_{Q 2} Q 2_{i t}+\frac{1}{2} \alpha_{Q 1 Q 1}\left(Q 1_{i t}\right)^{2}+\frac{1}{2} \alpha_{Q 2 Q 2}\left(Q 2_{i t}\right)^{2}+\frac{1}{2} \alpha_{Q 1 Q 2} Q 1_{i t} Q 2_{i t}+\alpha_{P L} P L_{i t} \\
& +\alpha_{C D} C D_{i t}+\alpha_{B C} B C_{i t}+\alpha_{L F} L F_{i t}+\alpha_{C U} C U_{i t}+\alpha_{T} T_{t}
\end{aligned}
$$

where subscripts $i$ and $t$ denote the company and year respectively. ${ }^{14}$ Normalized costs $C_{i t}$, the normalized factor price $P L$, output characteristics $C D, E C, L F$ and $C U$, and the time trend $T$ are introduced in a linear way (following Mayo - 1984). Finally $\alpha_{0}$ is the intercept. ${ }^{15}$

\section{Data and econometric specification}

The unbalanced panel data set contains financial and technical information from 74 companies observed during the nine-year period between 1997 and 2005. Thirty six companies are integrated with electricity distribution and hydropower generation, nine companies are only electricity distributors, and 29 companies are hydropower generators.

The data was collected from companies' annual reports and from the Swiss Federal Office of Energy (BFE - 2007). With this data set, we cover $42 \%$ of total electricity distribution and $40 \%$ of total hydropower generation in Switzerland.

The variables for the cost function specification were constructed as follows. Total costs $(C)$ are calculated as the total expenditures of the electricity generation and distribution firms in a

\footnotetext{
${ }^{13}$ This normalization has been obtained by demeaning all the included explanatory variables (subtracting from their mean values). Therefore, the intercept captures the total costs of production at the sample mean.

${ }^{14}$ We excluded the equation system approach with factor share equations as this approach also cannot easily be estimated using panel data econometric models.

${ }^{15}$ An extension of the quadratic cost function is the flexible fixed cost quadratic cost function suggested by Mayo (1984) and Panzar (1989). However, our additional estimations of this function showed that the estimated intercepts are not significantly different from each other and we therefore favoured the simpler model with a single intercept.
} 
given year, excluding expenditure for purchased electricity. ${ }^{16}$ The outputs are measured in Gigawatt hours (GWh) by the total quantity generated and delivered to the customers.

Input prices are defined as factor expenditures per factor unit. Labour price $(P L)$ is defined as the ratio of annual labour costs to the total number of employees as full time equivalent. Following Friedlaender and Chiang (1983) and Farsi et. al. (2008), the capital price (PC) is calculated as residual cost (where residual cost is total cost minus labour costs) divided by the capital stock, which is approximated here with the installed capacity of the generation assets and the maximal load of the network. ${ }^{17}$ The customer density $(C D)$ is measured by the number of customers divided by the network length measured in kilometres; $(E C)$, the share of the distributed electricity to end consumers is given as the percentage of sales to end consumers on total sales. The load factor $(L F)$ of the network is defined as the ratio of average and the maximum distribution per hour and the capacity utilization $(C U)$ is measured by the ratio of the average hourly generation per year and the installed generation capacity.

\footnotetext{
${ }^{16}$ See also Gilsdorf (1994) and (1995), Kwoka (2002), Jara-Diaz, Martinez-Budria et al. (2003), Filippini, Hrovatin et al. (2004), Jara-Diaz, Martinez-Budria et al. (2004) and Fraquelli, Piacenza et al. (2005) for defining the total costs as a net measure. Another approach was introduced by Kaserman and Mayo (1991) by using a total cost function including electricity purchases. However, this approach due to a double counting problem requires a modification of the definition of economies of vertical integration, that is not satisfactory.

${ }^{17}$ Due to a lack of data it was not possible to calculate the value of the assets by the perpetual inventory method. Other possibilities of a proxy for the capital stock is first the asset value from the annual reports of the companies, second the sum of installed generation capacity and the capacity of the transformers weighted by the specific investment costs and third the sum of the distributed and generated electricity (see Fraquelli, Piacenza et al. (2005)). However, the first suffers from different depreciation behaviors of the companies, the second from the lack of data and the third from the correlation with the output.
} 
Table 1: Descriptive statistics (570 observations)

\begin{tabular}{|c|c|c|c|c|c|c|}
\hline \multicolumn{2}{|c|}{ Variable } & \multirow{2}{*}{$\begin{array}{l}\text { Unit } \\
\text { CHF }\end{array}$} & \multirow{2}{*}{$\begin{array}{l}\begin{array}{l}\text { Mini- } \\
\text { mum }\end{array} \\
372^{\prime} 755\end{array}$} & \multirow{2}{*}{$\begin{array}{l}\text { Median } \\
17.7 \times 10^{6}\end{array}$} & \multirow{2}{*}{$\begin{array}{l}\text { Mean } \\
42.0 \times 10^{6}\end{array}$} & \multirow{2}{*}{$\begin{array}{l}\text { Maximum } \\
334 \times 10^{6}\end{array}$} \\
\hline$C$ & $\begin{array}{l}\text { Total cost without } \\
\text { electricity purchases }\end{array}$ & & & & & \\
\hline$Q 1$ & $\begin{array}{l}\text { Electricity genera- } \\
\text { tion }\end{array}$ & GWh & 0 & 66.4 & 206 & 1'790 \\
\hline$Q 2$ & $\begin{array}{l}\text { Electricity distribu- } \\
\text { tion }\end{array}$ & GWh & 0 & 50.2 & 624 & $10^{\prime} 346$ \\
\hline$P L$ & Labour price & CHF/employee & $58 ’ 483$ & $107^{\prime} 363$ & $105^{\prime} 710$ & $181 ’ 419$ \\
\hline$P C$ & Capital price & CHF/MW & $48 ’ 044$ & $214^{\prime} 762$ & $254^{\prime} 319$ & 837’655 \\
\hline$C D$ & Customer density & Customers/km & 0 & 14.8 & 20.6 & 174.9 \\
\hline$E C$ & $\begin{array}{l}\text { Share of distribution } \\
\text { to end consumers }\end{array}$ & $\%$ & 0 & 0.55 & 0.48 & 1 \\
\hline LF & $\begin{array}{l}\text { Load factor of the } \\
\text { network }\end{array}$ & $\%$ & 0 & 0.42 & 0.33 & 0.80 \\
\hline$C U$ & $\begin{array}{l}\text { Generation capacity } \\
\text { utilization }\end{array}$ & $\%$ & 0 & 0.41 & 0.40 & 0.91 \\
\hline
\end{tabular}

Table 1 provides the sample's descriptive statistics. All the costs and prices are adjusted for inflation using consumer price index and are measured in year 2000 Swiss Francs (CHF). As can be seen in the table, the sample shows a considerable difference in most of the variables.

With regard to the choice of econometric technique, it should be noted that in econometric literature we can find various types of panel data models focusing on cross-sectional variation, that is, heterogeneity across units. The two most widely used approaches are the fixed-effects model and the random effects model. ${ }^{18}$ Another econometric approach for panel data that is interesting in the presence of firm-specific unobserved heterogeneity is the RC model. In this model

\footnotetext{
${ }^{18}$ For a detailed presentation of the econometric methods that have been used to analyse panel data, see Greene (2003) and Baltagi (1995).
} 
the intercept and some or all explanatory variables are assumed to be random variables with a normal distribution across companies.

For the estimation of the quadratic cost function (2) we decided to use the random effects GLS model and the RC model. ${ }^{19}$ We excluded the fixed-effects approach for the following reasons.

- The data shows a relatively low within discrepancy (variation over time) in some of the variables, especially the outputs, customer density, and the load factor. As Cameron and Trivedi (2005) pointed out, the fixed-effects approach has an important weakness in that the coefficients of explanatory variables are 'very imprecise' if the variables' variation over time is dominated by that across companies (between variation). ${ }^{20}$

- As suggested by Hsiao (2003), the random effects is a better candidate for unconditional (population-averaged) analysis. ${ }^{21}$ As the estimation of economies of vertical integration relies on out-of-sample predictions of costs with some zero outputs, we have favoured the random effects framework over the fixed effects specification.

We are aware that in the random effects model, the individual effects might be correlated with explanatory variables, in which case the estimations might be affected by 'heterogeneity bias'. In order to overcome this potential problem at least partially, we decided to also use a RC model. The variation of the coefficients of this specification should capture part of the correlation of the random intercept with the corresponding variables. In the RC model the two output coefficients and the intercept are assumed to be random variables with normal distribution across companies. The RC model has been estimated using a simulated maximum likelihood method.

\footnotetext{
${ }^{19}$ The result of a Breusch-Pagan Lagrange Multiplier test showed that individual effects exist and therefore no pooled OLS model should be used.

${ }^{20}$ Johnston and DiNardo (1997) also show that the 'attenuation' bias due to measurement errors is exacerbated in the fixed-effects models depending on the fraction of the within variation due to 'mismeasurement' especially when the explanatory variables are correlated across time. In our case both reporting errors and correlation across time are plausible.

${ }^{21}$ See also Cameron and Trivedi (2005) and Verbeek (2004) for a discussion of this issue.
} 


\section{Results}

The estimation results obtained from the GLS model and the RC model are given in Table 2. For the RC model, estimated with the simulated likelihood method using pseudo-random Halton draws, it is assumed that the intercept and the first-order coefficients of output vary across companies. ${ }^{22}$

The results reported in Table 2 show that generally the coefficients reported for both models have the expected sign and are significant and similar in magnitude. For instance, the output and input price coefficients are highly significant and have the expected positive sign. The effect of customer density (coefficient $\alpha_{\mathrm{CD}}$ ) is negative, showing that an increase in the customer density decreases costs. The coefficient of the share of sales to end consumers $\left(\alpha_{\mathrm{EC}}\right)$ is, as expected, positive in all models. The load factor of the network $\alpha_{\mathrm{LF}}$ and the capacity utilization factor $\alpha_{\mathrm{CU}}$ are negative, suggesting that a higher peak load profile leads ceteris paribus to higher costs. Finally, in the GLS model the coefficient of the linear time trend suggests a cost decrease in the electricity sector over the observed period, whereas in the RC model this coefficient is not statistically significant.

\footnotetext{
${ }^{22}$ The number of draws has been fixed to 1000 . The model was also estimated with several numbers of draws between 100 and 1,000. The results indicate that after 500 draws, the estimations become stable.
} 
Table 2: Regression results

\begin{tabular}{|c|c|c|c|c|}
\hline & \multicolumn{2}{|c|}{$\begin{array}{l}\text { Normalized quadratic cost function } \\
\text { (RE GLS model) }\end{array}$} & \multicolumn{2}{|c|}{$\begin{array}{l}\text { Normalized quadratic cost function } \\
\text { (Random coefficient model) }\end{array}$} \\
\hline & Coefficient & z-statistics & Coefficient & z-statistics \\
\hline$\alpha_{\mathrm{Q} 1}$ & $0.23^{*}$ & (1.93) & $0.51^{* * *}$ & $(74.62)$ \\
\hline$\alpha_{\mathrm{Q} 2}$ & $0.42 * * *$ & (14.54) & $0.39 * * *$ & (14.99) \\
\hline$\alpha_{\mathrm{Q} 1 \mathrm{Q} 1}$ & $0.00033^{*}$ & (1.84) & $-51.30 \times 10^{-6} * * *$ & $(-12.84)$ \\
\hline$\alpha_{\mathrm{Q} 2 \mathrm{Q} 2}$ & $-0.00006^{* * *}$ & $(-10.52)$ & $-97.02 \times 10^{-6}$ & $(-1.33)$ \\
\hline$\alpha_{\mathrm{Q} 1 \mathrm{Q} 2}$ & $-0.00004 *$ & $(-1.68)$ & $-55.71 \times 10^{-6} * * *$ & $(-5.23)$ \\
\hline$\alpha_{\mathrm{PL}}$ & $52.99 * * *$ & $(8.18)$ & $50.11^{* * *}$ & (19.68) \\
\hline$\alpha_{\mathrm{PC}}$ & - & & - & \\
\hline$\alpha_{\mathrm{CD}}$ & $-1.86^{* *}$ & $(-2.27)$ & $-2.80 * * *$ & $(-19.82)$ \\
\hline$\alpha_{\mathrm{EC}}$ & $236 * * *$ & (2.64) & $511 * * *$ & (23.64) \\
\hline$\alpha_{\mathrm{LF}}$ & -218 & $(-1.62)$ & $-471.71 * * *$ & $(-13.15)$ \\
\hline$\alpha_{\mathrm{CU}}$ & $-124 *$ & $(-1.90)$ & $-109.27 * * *$ & $(-7.09)$ \\
\hline$\alpha_{\mathrm{T}}$ & $-4.81 * * *$ & $(-2.91)$ & $-3.62 * * *$ & $(-2.92)$ \\
\hline$\alpha_{0}$ & $418^{* * *}$ & (15.05) & $530.46 * * *$ & $(130.85)$ \\
\hline$\hat{\sigma}_{u}$ & 204.99 & & - & \\
\hline \multirow[t]{2}{*}{$\hat{\sigma}_{\varepsilon}$} & 78.98 & & - & \\
\hline & Overall R2 & 0.80 & $\begin{array}{l}\text { McFadden } \\
\text { pseudo R2 }\end{array}$ & 0.24 \\
\hline \multicolumn{5}{|c|}{ Standard deviation (SD) for random parameters ${ }^{(a)}$} \\
\hline$\alpha_{0}$ & - & & $115.08 * * *$ & (39.88) \\
\hline$\alpha_{\mathrm{Q} 1}$ & - & & $0.15^{* * *}$ & $(51.83)$ \\
\hline$\alpha_{\mathrm{Q} 2}$ & - & & $1.41^{* * *}$ & (52.71) \\
\hline
\end{tabular}

$* * *$, ** and * indicate $1 \%, 5 \%$ and $10 \%$ significance level respectively.

The coefficient reported for each random parameter is the mean;

(a) we report estimates of SD of normal distribution of random parameters.

Furthermore, the estimated standard deviations of the RC are all statistically significant for the two outputs as well as for the intercept. This suggests that there is a significant variation in 
the output coefficients and the intercept across companies. The estimates of the variances of the random effects show that there is a considerable unobserved firm-specific heterogeneity.

The estimation results presented in Table 2 can be used to compute the estimated values of the economies of vertical integration and (product-specific) economies of scale. These results, along with a formal description of the concepts, will be presented in the following section.

\section{Economies of vertical integration and economies of scale}

Following Baumol, Panzar et al. (1982) the global economies of scale (ES) in a multioutput setting are defined as:

$$
E S=\frac{C(Q 1, Q 2)}{Q 1 * \frac{\partial C}{\partial Q 1}+Q 2 * \frac{\partial C}{\partial Q 2}}
$$

where $C(Q 1, Q 2)$ is the total cost of producing $Q 1$ and $Q 2, \partial \mathrm{C} / \partial Q 1$ is the marginal cost of producing product $Q 1, \partial \mathrm{C} / \partial Q 2$ is the marginal cost of producing product $Q 2$.

Global economies of scale describe the cost behaviour caused by proportional changes in the entire production. Economies of scale prevail if $E S$ is greater than 1 and, accordingly, diseconomies of scale exist if $E S$ is below 1. In the case of $E S=1$ no economies or diseconomies of scale exist.

In addition, product-specific economies of scale are based on changes of one output or an output pair, while all other outputs are held constant. Product-specific economies of scale to the product $m$ are defined as (see Baumol, Panzar et al. (1982)):

$$
S L_{m}=\frac{C(Q 1, Q 2)-C\left(Q_{-m}\right)}{Q_{m} * \frac{\partial C}{\partial Q_{m}}},
$$

where $C(Q 1, Q 2)-C\left(Q_{-m}\right)$ represents the incremental cost resulting from producing output $m$ and $C\left(Q_{-m}\right)$ is the costs of producing all the outputs jointly except output $m$.

Economies of vertical integration (EVI) are present when costs can be reduced by joint production of multiple outputs across different production stages. Following the Baumol, Panzar 
et al. (1982) concept of economies of scope, the degree of EVI across two stages can be defined as the ratio of excess costs of separate production to the costs of joint production in one company:

$$
E V I=\frac{C(Q 1,0)+C(0, Q 2)-C(Q 1, Q 2)}{C(Q 1, Q 2)}
$$

where $C(Q 1,0)$ is the total cost when output for product $Q 2$ is zero. Similarly, C $(0, Q 2)$ is the total cost when output for product $Q 1$ is zero. A positive (negative) value for the above expression implies the existence of economies (diseconomies) of vertical integration.

Using Equations (3) and (5), and the regression results, the values of EVI and scale economies have been estimated for all companies. It is important to underline that a correct estimation of EVI relies on adequate prediction of costs at certain points that are at the sample boundary or completely out of the sample. The precision of such predictions depends on the econometric specification. As discussed earlier, a GLS model provides a relatively accurate outof-sample prediction. The random-coefficient model has an additional advantage with respect to heterogeneity bias in the coefficients.

Table 3 provides a descriptive summary of the distribution of the estimates of the EVI and scale across the companies included in the sample. The results obtained from both GLS and RC models are listed. In both models, the firm-specific random effects are included in the calculation of economies of scale and vertical integration. ${ }^{23}$ Moreover, for the computation of the economies of scale and vertical integration, the input prices and output characteristics are considered at their individual level.

Both GLS and RC estimates suggest the existence of economies of vertical integration and scale economies across a major part of the sample. Looking across the numbers from both models indicates that the majority of the companies exhibit economies of vertical integration and economies of scale. It has to be considered that the majority of companies considered in the

\footnotetext{
${ }^{23}$ With respect to other studies, in this paper we consider in the computation of the values of the economies of vertical integration and economics of scale the estimates of firm-specific individual effects, namely the conditional expectation of the random intercept and random coefficients. Of course, we are aware that such company-level estimates may entail relatively large estimation errors at the individual level. However, we believe that this approach based on actual levels of outputs, network characteristics and individual unobserved heterogeneity reflects in a better way the characteristics of the production technology rather than an approach that calculates the values of the economies of vertical integration using some values for a series of hypothetical companies.
} 
empirical analysis have less than 100,000 customers. This implies that these results apply mainly for small and middle-sized companies.

Table 3: Distribution of economies of vertical integration and economies of scale estimated for individual companies (normalized quadratic cost function)

\begin{tabular}{|l|c|c|c|c|}
\hline & \multicolumn{2}{|c|}{ Economies of vertical integration } & \multicolumn{2}{c|}{ Economies of scale } \\
\hline & RE GLS & RC & RE GLS & RC \\
\hline 20th percentile & 0.30 & 0.13 & 0.98 & 0.94 \\
\hline 40th percentile & 0.64 & 0.40 & 1.40 & 1.23 \\
\hline 60th percentile & 0.74 & 0.59 & 2.05 & 1.53 \\
\hline 80th percentile & 1.06 & 1.13 & 3.21 & 2.21 \\
\hline
\end{tabular}

A comparison of the results of the GLS model and the RC model in the 3 also shows that the RC model provides a lower estimate of both economies, as seen in slightly lower values for most of the percentiles. This could be explained by the fact that the RC model gives a relatively lower weight to differences regarding fixed costs because part of these costs might be captured by random coefficients. However, we could not find any conclusive pattern suggesting a one-sided bias because of ignoring such unobserved heterogeneity.

Table 4 shows the product-specific economies of scale of the RE GLS model and the RC model. These results confirm the presence of product-specific economies of scale.

Table 4: Distribution of the product-specific economies of scale estimated for individual companies (normalized quadratic cost function)

\begin{tabular}{|l|l|c|c|c|}
\hline & \multicolumn{2}{|c|}{ Generation } & \multicolumn{2}{c|}{ Distribution } \\
\hline & RE GLS & RC & RE GLS & RC \\
\hline 20th percentile & 0.77 & 1.00 & 1.00 & 1.00 \\
\hline 40th percentile & 0.86 & 1.00 & 1.01 & 1.01 \\
\hline 60th percentile & 0.94 & 1.02 & 1.03 & 1.01 \\
\hline 80th percentile & 0.99 & 1.06 & 1.12 & 1.10 \\
\hline
\end{tabular}




\section{Conclusions}

Using a panel data set from Swiss electricity companies operating in the distribution and generation stage, this paper has studied the economies of vertical integration and economies of scale. For this purpose, a quadratic multi-stage cost function has been estimated using two econometric specifications for panel data - a random effects panel data (GLS) model and a random-coefficient (RC) model. These models have been chosen to consider the effect of unobserved heterogeneity across different electricity distributors and generators on the values of the economies of scale and economies of vertical integration.

While the GLS model considers unobserved heterogeneity as various costs shift across companies, the RC model includes variations in the coefficients of the outputs. Compared to a simple pooled model, the GLS specification provides a better control for omitted variables. The

RC model provides an additional improvement regarding the potential heterogeneity bias in the coefficients’ estimates.

The empirical results confirm the existence of significant economies of vertical integration and economies of scale for a majority of the electricity companies considered in the sample. This suggests that additional costs could result from unbundling vertically integrated companies. Further, the values of the economies of scale and of vertical integration show a considerable variation among individual companies. This variation is due partially by the difference among companies in the values of the observed heterogeneity and partially by the difference of the coefficients capturing the unobserved heterogeneity. Thus, this result underlines the importance of considering unobserved network and environmental characteristics in the econometric specification.

From the policy point of view, these empirical results support the EU policy directive that provides member states the possibility to exempt companies with fewer than 100,000 customers from any functional unbundling requirement. Moreover, this result supports the decision taken by the Swiss Government to not force the introduction of a functional unbundling for the small and middle sized Swiss vertical integrated companies.

Finally, the analysis reported in this paper suggests that unbundling processes reduce the possibilities to exploit the advantages of vertical integration. This means that policymakers should be generally more concerned about the efficient balance between integration and unbundling, also for larger companies for which no empirical evidence is available. 


\section{References}

Asteriou, D. and S. G. Hall (2007). Applied econometrics: A modern approach. New York: Palgrave Macmillan.

Baumol, W. J., J. C. Panzar and R. D. Willig (1982). Contestable Markets and the Theory of Industry Structure. New York: Hartcourt Brace Jovanovich.

BFE (2007). Statistik der Wasserkraftanlagen der Schweiz (WASTA), Bundesamt für Energie, Bern.

Biørn, E., K.-G. Lindquist and T. Skjerpen (2002). "Heterogeneity in Returns to Scale: A Random Coefficient Analysis with Unbalanced Panel Data." Journal of Productivity Analysis 18(1): 39-57.

Cameron, A. C. and P. K. Trivedi (2005). Microeconometrics Methods and Applications. Cambridge: Cambridge University Press.

Caves, D. W., L. R. Christensen and M. W. Tretheway (1980). "Flexible Cost Functions for Multiproduct Firms." Review of Economics and Statistics 62(3): 477-81.

Chamberlain, G. (1982). "Multivariate Regression Models for Panel Data." Journal of Econometrics 18(1): 5-46.

Cord, M., B. Hannes, B. Hartmann, J. Kellerhoff and D. Weber-Rey (2003). "Konsequenzen der Unbundling-Vorgaben für die deutsche Energiewirtschaft - Skizze möglicher Umsetzungsmodelle und Hypothesen zum Marktauftritt." Zeitschrift für Energiewirtschaft 27(4): 251-9.

Farsi, M., A. Fetz and M. Filippini (2007). "Economies of Scale and Scope in Local Public Transportation." Journal of Transport Economics and Policy 41(3): 345-61.

Farsi, M., A. Fetz and M. Filippini (2008). Economies of Scale and Scope in the Swiss MultiUtilities Sector, Energy Journal, 29 (4): 123-143.

Featherstone, A. M. and C. B. Moss (1994). "Measuring Economies of Scale and Scope in Agricultural Banking." American Journal of Agricultural Economics 76(3): 655-61.

Filippini, M. (1996). "Economies of Scale and Utilization in the Swiss Electric Power Distribution Industry." Applied Economics 28(5): 543-50.

Filippini, M. (1998). "Are Municipal Electricity Distribution Utilities Natural Monopolies?" Annals of Public and Cooperative Economics 69(2): 157-74.

Filippini, M., N. Hrovatin and J. Zoric (2004). "Efficiency and regulation of the Slovenian electricity distribution companies." Energy Policy 32(3): 335-44.

Fraquelli, G., M. Piacenza and D. Vannoni (2004). "Scope and Scale Economies in MultiUtilities: Evidence from Gas, Water and Electricity Combinations." Applied Economics 36(18): 2045-57.

Fraquelli, G., M. Piacenza and D. Vannoni (2005). "Cost Savings from Generation and Distribution with an Application to Italian Electric Utilities." Journal of Regulatory Economics 28(3): 289-308.

Friedlaender, A. F. and W. Chiang (1983). "Productivity Growth in the Regulated Trucking Industry." Research in Transportation and Economics 1: 149-84.

Gilsdorf, K. (1994). "Vertical Integration Efficiencies and Electric Utilities: A Cost Complementarity Perspective." Quarterly Review of Economics and Finance 34(3): 261-82. 
Gilsdorf, K. (1995). "Testing for Subadditivity of Vertically Integrated Electric Utilities." Southern Economic Journal 62(1): 126-38.

Greer, M.L., (2008). "A test of vertical economies for non-vertically integrated firms: The case of rural electric cooperatives, "Energy Economics 30 679-687

Hayashi, P. M., J. Y.-J. Goo and W. C. Chamberlain (1997). "Vertical Economies: The Case of U.S. Electric Utility Industry, 1983-87." Southern Economic Journal 63(3): 710-25.

Hsiao, C. (2003). Analysis of panel data. Cambridge: Cambridge University Press.

Ida, T. and T. Kuwahara (2004). "Yardstick Cost Comparison and Economies of Scale and Scope in Japan's Electric Power Industry." Asian Economic Journal 18(4): 423-38.

Isaacs, J. P. (2006). Determining the Regulatory Impact on Vertical Economies in the Electric Utility Industry, Fourth Annual International Industrial Organization Conference, Boston, Massachusetts.

Jara-Diaz, S. R., E. Martinez-Budria and F. J. Ramos-Real (2003). "Adapting Productivity Theory to the Quadratic Cost Function: An Application to the Spanish Electric Sector." Journal of Productivity Analysis 20(2): 213-29.

Jara-Diaz, S. R., E. Martinez-Budria and F. J. Ramos-Real (2004). "Economies of integration in the Spanish electricity industry using a multistage cost function." Energy Economics 26(6): 995-1013.

Johnston, J. and J. DiNardo (1997). Econometric methods. New York: McGraw-Hill.

Kaserman, D. L. and J. W. Mayo (1991). "The Measurement of Vertical Economies and the Efficient Structure of the Electric Utility Industry." Journal of Industrial Economics 39(5): 483-502.

Kwoka, J. E. (2002). "Vertical economies in electric power: evidence on integration and its alternatives." International Journal of Industrial Organization 20(5): 653-71.

Lee, B.-J. (1995). "Separability Test for the Electricity Supply Industry." Journal of Applied Econometrics 10(1): 49-60.

Maloney, M. T. (2001). "Economies and Diseconomies: Estimating Electricity Cost Functions." Review of Industrial Organization 19(2): 165-80.

Michaels, R. J. (2004). "Vertical Integration: The Economics that Electricity Forgot." The Electricity Journal 12(2): 11-23.

Mayo, J. W. (1984). "Multiproduct Monopoly, Regulation, and Firm Costs." Southern Economic Journal 51(1): 208-18.

Panzar, J. C. (1989). Technological Determinants of Firm and Industry Structure, Handbook of Industrial Organization, R. Schmalensee and R. D. Willig, Amsterdam, Elsevier, Volume 1: 3-59.

Pulley, L. B. and Y. M. Braunstein (1992). "A Composite Cost Function for Multiproduct Firms with an Application to Economies of Scope in Banking", Review of Economics and Statistics 74(2): 221-30.

Pulley, L. B. and D. B. Humphrey (1993). "The Role of Fixed Costs and Cost Complementarities in Determining Scope Economies and the Cost of Narrow Banking Proposals." Journal of Business 66(3): 437-62.

Sing, M. (1987). "Are combination Gas and Electric Utilities multiproduct natural Monopolies?" Review of Economics and Statistics 69(3): 392-8. 
Tovar, B., S. R. Jara-Diaz and L. Trujillo (2007). "Econometric Estimation of Scale and Scope Economies within the Port Sector: A Review." Maritime Policy \& Management 34(3): 203-23.

Verbeek, M. (2004). A guide to modern econometrics. Chichester: Wiley.

Yatchew, A. (2000). "Scale Economies in Electricity Distribution: A Semiparametric Analysis." Journal of Applied Econometrics 15(2): 187-210. 